\title{
Efficacy of anti-VEGF agents in the treatment of elderly hepatocellular carcinoma: a systematic review
}

\author{
Xiaofei Li ${ }^{1}$, Daofu Zhang ${ }^{2}$, Shan Guan ${ }^{3}$, Weiwei Ye ${ }^{1}$, Liwen Liu ${ }^{1}$ and Lianqing Lou ${ }^{1}$ \\ ${ }^{1}$ Department of Infectious Diseases, Yi Wu Central Hospital, Zhejiang Province, 322000, China \\ ${ }^{2}$ Liao Cheng City People's Hospital, Shandong Province, 252000, China \\ ${ }^{3}$ Department of Infectious Diseases, Liaocheng People's Hospital, Shandong Province, 252000, China \\ Correspondence to: Xiaofei Li, email: xiaofeili2017@sohu.com
}

Keywords: hepatocellular carcinoma, elderly, randomized controlled trials, meta-analysis

Received: April 27, $2017 \quad$ Accepted: July 12, $2017 \quad$ Published: October 03, 2017

Copyright: Li et al. This is an open-access article distributed under the terms of the Creative Commons Attribution License 3.0 (CC BY 3.0), which permits unrestricted use, distribution, and reproduction in any medium, provided the original author and source are credited.

\section{ABSTRACT}

Purpose: We aimed to investigate the role of anti-vascular endothelial growth factor (VEGF) agents, including tyrosine-kinase inhibitors or monoclonal anti-bodies, in the treatment of elderly hepatocellular carcinoma (HCC) patients.

Materials and Methods: Databases from PubMed, Web of Science and abstracts presented at ASCO meeting up to March 31, 2017 were searched to identify relevant studies. The endpoints were overall survival (OS) and progression-free survival (PFS). Data were examined using age cutoffs of 65 years.

Results: A total of 1,309 elderly (aged $\geq 65$ years) HCC patients from seven trials were included for analysis. Our results demonstrated that the use of anti-VEGF agents MTAs in patients aged $\geq 65$ years significantly improved PFS (HR $0.65,95 \%$ CI: $0.55-0.76, p<0.001$ ) but not for OS (HR 0.87, 95\% CI: $0.73-1.05, p=0.15$ ). Subgroup analysis according to treatment line showed that the use of anti-VEGF agents as second-line treatment significantly improved PFS (HR 0.55, 95\% CI: 0.45-0.67, $p<0.001$ ) and marginally improved OS (HR 0.83, 95\% CI: $0.68-1.01, p=0.061$ ). Additionally, no survival benefits were observed in elderly HCC received first-line anti-VEGF treatments in terms of PFS (HR 0.87, 95\% CI: $0.67-1.13, p=0.29$ ) and OS (HR 1.19, 95\% CI: 0.74-1.36, $p=0.47$ ). No publication bias was detected by Begg's and Egger's tests for OS.

Conclusions: The findings of this study show that elderly HCC patients who relapsed after a first-line sorafenib treatment obtains a survival benefits from antiVEGF agents rechallenge. Further studies are recommended to search for predictors of good responders in these patients received anti-VEGF agents.

\section{INTRODUCTION}

Hepatocellular carcinoma (HCC) is one of the leading causes of cancer-related deaths with an estimated 748,300 new liver cancer cases and 695,900 cancer deaths occurred worldwide [1,2]. Surgical resection and liver transplantation are considered the only potentially curative treatment for HCC patients. However, more than $70 \%$ of $\mathrm{HCC}$ patients present with intermediatestage or advanced-stage disease at the time of diagnosis, and therefore are not suitable for surgical resection [3].
The prognosis of advanced HCC patients is dismal with a median overall survival time of about 7 months [4]. Novel treatments for HCC patients are clearly needed. Additionally, HCC usually develops in patients with hepatitis $\mathrm{B}$ virus infection, hepatitis $\mathrm{C}$ virus infection, or alcoholic liver disease, which develops over a long period of time [5,6]. Additionally, the widely use of anti-viral therapy might further delay the development of HCC. As a result, $\mathrm{HCC}$ is commonly diagnosed in middle-aged and elderly populations, and management of elderly HCC patients is becoming a global issue $[5,7]$. 
Angiogenesis, the formation of new blood vessels, is known to play a central role in the progression of many solid tumors, including HCC [8-10]. Among the many mediators of new blood vessel formation, vascular endothelial growth factor (VEGF) family of ligands plays a primary role $[11,12]$. Inhibition of VEGF signaling pathway has proven an effective strategy for the treatment of HCC patients [13] and other solid tumors [14-18]. Until now, sorafenib is the only systematic treatment approved by FDA for use in advanced HCC patients [19-21]. Additionally, several novel anti-VEGF agents have been extensively assessed in many prospective clinical trials [22-25]. However, as the stringent enrolment criteria for patients in prospective trials, the enrolled elderly patients in clinical studies are not entirely representative of the overall elderly patient population. In addition, treatment of elderly HCC patients may be complicated by several comorbid conditions and greater concomitant medication use when compared to younger patients $[26,27]$. As a result, clinical data obtained from a selected elderly population cannot be automatically extrapolated to the great majority of non-selected elderly HCC patients.

Currently, there is still no general agreement on the definition of the elderly population. Most developed countries accept the chronological age of 65 years as the definition of an elderly person. In the present, we agree with the cut-off of $\geq 65$ years to refer to the older population. As the elderly HCC population increases, it is urgently needed to define the best treatment strategy for these patients. We thus perform the present study to assess the efficacy of anti-VEGF agents in the treatment of elderly HCC patients.

\section{MATERIALS AND METHODS}

\section{Search strategy}

A comprehensive search for relevant articles was conducted in databases including the Pubmed, Embase and the Cochrane Library electronic databases (Supplementary Table 1). The date of the last search was 31 January 2017. Articles with the following test words in their titles, abstracts or keywords were examined: "anti-VEGF agents", "angiogenesis inhibitors", "sorafenib", "sunitinib", "regorafenib", "ramucirumab", "axitinib", "brivanib", "hepatocellular carcinoma", "randomized controlled trials". An independent search of the Google scholar was also performed to ensure that no additional clinical trials had been overlooked. If more than one publication was found for the same trial, the most complete, recent, and updated report of the clinical trial was included. Ethical approval for this study was not unnecessary since it was a meta-analysis that collected and analyzed data from the existing literatures.

\section{Study selection}

Clinical trials that met the following criteria were included: (1) randomized controlled phase II and III trials in patients with $\mathrm{HCC}$; (2) participants assigned to treatment with or without anti-VEGF agents; (3) survival data of elderly patients were available;

\section{Data extraction}

Two authors independently performed data extraction. This meta-analysis was conducted in accordance with the Preferred Reporting Items for Systematic review and Meta-Analysis (PRISMA) statement (Supplementary Table 2) [28]. Disagreements between investigators were resolved by discussion and consensus. A standardized Excel file was used for data extraction. The following data were extracted: first author, publication year, the number of enrolled patients and elderly patients, median age, hazard ratios (HRs) with $95 \%$ confidence intervals (CIs) for OS and PFS in elderly HCC patients.

\section{Clinical end point and statistical method}

The outcome measures of interest were progressionfree survival (PFS) and overall survival (OS). PFS and OS were considered as time-to-event variables, and therefore were expressed as HRs with $95 \%$ CIs for each study. HR $>1$ reflected more deaths or progression in anti-VEGFcontaining regimens, and vice versa. Heterogeneity across the studies was assess by using the $\chi^{2}$-based Q statistic [29]. The $I^{2}$ statistic was also calculated to quantitatively evaluate the degree of inconsistency between trials. Predefined sub-group analysis according to treatment line was performed. We used the Begg and Egger tests to assess the presence of publication bias [30]. Study quality was roughly assessed by using the Jadad five-item scale [31]. All $p$-value of less than 0.05 was considered statistically significant. All statistical analysis was calculated using Version 2 of the Comprehensive MetaAnalysis program (Biostat, Englewood, NJ).

\section{RESULTS}

Our search strategy yielded 110 clinical studies related to anti-VEGF agents in HCC patients from databases. The reasons for study exclusion were shown in Figure 1. Finally, a total of seven prospective randomized controlled trials were considered eligible, including one phase II trials [32] and six phase III trials [33-38]. A total of 1,309 elderly (aged $\geq 65$ years) HCC patients were included. The characteristics of patients and studies were listed in Table 1. The quality of each included study was roughly assessed according to Jadad scale, and the median Jadad score of the included studies was 5 (range 3-5). 
Table 1: Baseline characteristics of seven included randomized controlled trials

\begin{tabular}{|c|c|c|c|c|c|c|c|c|c|}
\hline Authors/year & Phase & Total & $\begin{array}{l}\text { Cutoff of } \\
\text { age }\end{array}$ & $\begin{array}{l}\text { No. of } \\
\text { patients }\end{array}$ & Treatment arms & $\begin{array}{l}\text { median } \\
\text { age } \\
\text { (years) }\end{array}$ & $\begin{array}{l}\text { median } \\
\text { PFS, } m\end{array}$ & $\begin{array}{l}\text { median } \\
\text { OS, m }\end{array}$ & $\begin{array}{l}\text { Jadad } \\
\text { Score }\end{array}$ \\
\hline \multirow[t]{2}{*}{ Cheng AL, et al. 2009} & III & 271 & $\geq 65$ & 32 & Sorafenib $400 \mathrm{mg}$ bid po & 51 & 2.8 & 6.5 & 5 \\
\hline & & & & & placebo & 52 & 1.4 & 4.2 & \\
\hline \multirow[t]{2}{*}{ Kudo M, et al. 2011} & III & 458 & $\geq 65$ & 152 & Sorafenib $400 \mathrm{mg}$ bid po + TACE & 69 & 5.4 & 29.7 & 5 \\
\hline & & & & & Placebo + TACE & 70 & 3.7 & NR & \\
\hline \multirow[t]{2}{*}{ Kudo M, et al. 2014} & III & 502 & $\geq 65$ & 159 & Brivanib $800 \mathrm{mg}$ qd po & 57 & 12 & 26.4 & 5 \\
\hline & & & & & Placebo & 59 & 10.9 & 26.1 & \\
\hline \multirow[t]{2}{*}{ Bruix J, et al. 2015} & III & 1114 & $\geq 65$ & 370 & Sorafenib $400 \mathrm{mg}$ bid po & 58 & 8.5 & NR & 5 \\
\hline & & & & & Placebo & 60 & 8.4 & NR & \\
\hline \multirow[t]{2}{*}{ Kang YK, et al. 2015} & II & 202 & $\geq 65$ & 85 & Axitinib $5 \mathrm{mg}$ bid po & 61 & 3.6 & 12.7 & 3 \\
\hline & & & & & Placebo & 63 & 1.9 & 9.7 & \\
\hline \multirow[t]{2}{*}{ Zhu AX, et al. 2015. (REACH) } & III & 565 & $\geq 65$ & 253 & Ramucirumab 8 mg/kg & 64 & 2.8 & 9.2 & 5 \\
\hline & & & & & Placebo & 62 & 2.1 & 7.6 & \\
\hline \multirow[t]{2}{*}{ Bruix J, et al. 2017} & III & 573 & $\geq 65$ & 258 & Regorafenib 160 mg po & 64 & 3.1 & 10.6 & 5 \\
\hline & & & & & Placebo & 62 & 1.5 & 7.8 & \\
\hline
\end{tabular}

Abbreviations: OS, overall survival; PFS, progression-free survival; TACE, transcatheter arterial chemoembolization; NR, not reported.

\section{Progression-free survival}

Four trials of the eight trials reported PFS data in the study patients. The pooled results demonstrated that the use of anti-VEGF agents significantly improved PFS in elderly HCC patients giving HR 0.65 (95\% CI: $0.55-0.76, p<0.001$, Figure 2). Sub-group analysis according to treatment line showed that the use of antiVEGF agents significantly improved PFS in elderly HCC patients who relapsed after a first-line sorafenib treatment (HR 0.55, 95\% CI: 0.45-0.67, $p<0.001$, Figure 2), while the use of anti-VEGF agents as first-line treatment did not significantly improved PFS in this patients population (HR 0.87, 95\% CI: 0.67-1.13, $p=0.29$ ). Begg's test and Egger's test revealed no evidence of obvious publication bias ( $p=0.50$ and $p=0.56$, respectively).

\section{Overall survival}

Five of the seven trials reported OS data of elderly patients. Our pooled results demonstrated that the use of anti-VEGF agents did not significantly improved

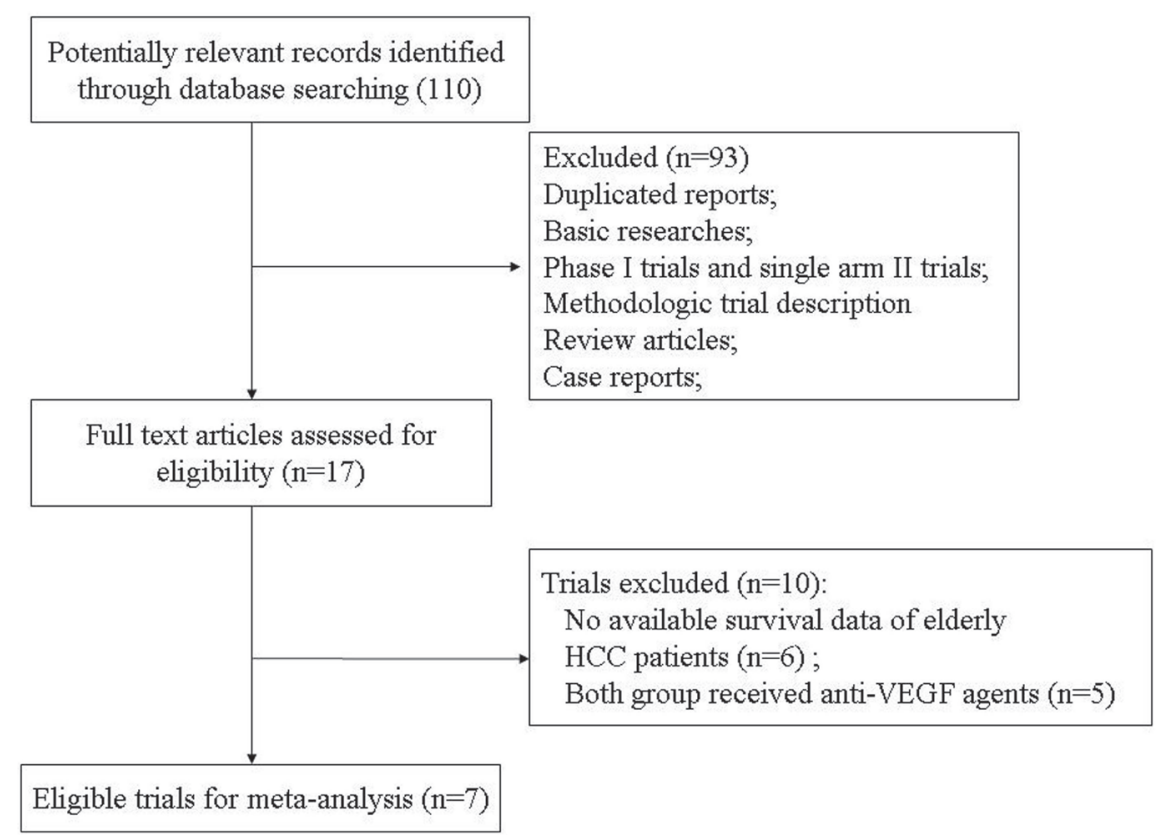

Figure 1: Studies eligible for inclusion in the meta-analysis. 
OS in elderly HCC patients giving HR of 0.87 (95\% CI: $0.73-1.05, p=0.15$ Figure 3). However, sub-group analysis showed that the anti-VEGF agents rechallenge marginally improved OS in elderly (aged $\geq 65$ years) HCC patients who previously treated with sorafenib (HR 0.83 , 95\% CI: $0.68-1.01, p=0.061$ ), while no survival benefit was obtained in elderly HCC received first-line anti-VEGF treatment (HR 1.19, 95\% CI: 0.74-1.90, $p=0.47$ ). Begg's test and Egger's test revealed no evidence of obvious publication bias ( $p=0.33$ and $p=0.38$, respectively).

\section{DISCUSSION}

In the past years, the mechanisms of hepatocarcinogenesis have been extensively investigated. Several tyrosine-kinase receptors, including vascular endothelial growth factor receptor (VEGFR), plateletderived growth factor receptor (PDGFR), and the scatter growth factor receptor MET, have been implicated in the proliferation and invasion of HCC. HCC tumors are highly vascularized, and vascular endothelial growth factor (VEGF) augments HCC development and metastasis [39]. Vascular endothelial growth factor A (VEGF-A) promotes angiogenesis primarily through binding and activation of the receptor VEGFR-2 [40]. VEGF-A is frequently overexpressed in $\mathrm{HCC}$, and is related with blood vessel density and tumor recurrence [40]. Makinen T. reported that VEGF-C/VEGFR-3 signaling pathway played a critical role in the growth and survival of lymphatic endothelial cells [41]. These findings suggest that inhibition of VEGF signaling pathway might be an effective strategy for the treatment of HCC patients. Sorafenib, a multikinase inhibitor of VEGFR, PDGFR- $\beta$, Raf, and other kinases has been shown to be efficacious against HCC, and has been approved as first-line treatment of advanced HCC. Several anti-VEGF agents also represent a promising treatment strategy to improve outcome of advanced HCC patients. A previous metaanalysis conducted by Niu M. et al. [42] showed that the use of anti-VEGF therapies in HCC patients significantly improved survival in comparison with placebo. However, there is limited data specifically focusing on the efficacy of anti-VEGF agents in elderly patients with HCC. As a result, we perform the present study to investigate the overall efficacy of anti-VEGF agents in the treatment of elderly HCC patients.

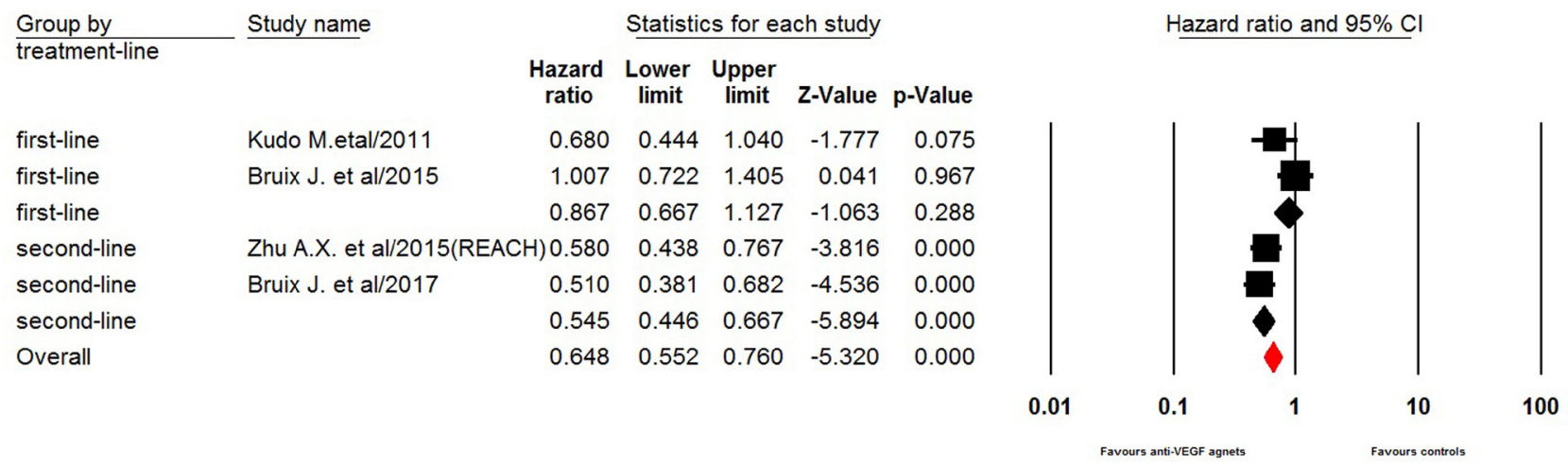

Figure 2: Fixed-effects model of hazard ratio $(95 \%$ CI) of PFS associated with therapy with or without anti-VEGF agents.

\begin{tabular}{|c|c|c|c|c|c|c|c|c|}
\hline \multirow{2}{*}{$\frac{\text { Group by }}{\text { line }}$} & \multirow[t]{2}{*}{ Study name } & \multicolumn{5}{|c|}{ Statistics for each study } & & Hazard ratio and $95 \% \mathrm{Cl}$ \\
\hline & & $\begin{array}{l}\text { Hazard } \\
\text { ratio }\end{array}$ & $\begin{array}{c}\text { Lower } \\
\text { limit }\end{array}$ & $\begin{array}{l}\text { Upper } \\
\text { limit }\end{array}$ & Z-Value & p-Value & & \\
\hline first-line & Cheng A.L. et al/2009 & 0.740 & 0.321 & 1.706 & -0.707 & 0.480 & & \\
\hline first-line & Kudo M.etal/2014 & 1.480 & 0.840 & 2.609 & 1.356 & 0.175 & & \\
\hline first-line & & 1.189 & 0.744 & 1.901 & 0.725 & 0.469 & & \\
\hline second-line & Kang Y.K. et al/2015 & 1.094 & 0.657 & 1.821 & 0.345 & 0.730 & & \\
\hline second-line & Zhu A.X. et al/2015(REACH) & 1) 0.830 & 0.620 & 1.111 & -1.254 & 0.210 & & \\
\hline second-line & Bruix J. et al/2017 & 0.740 & 0.538 & 1.017 & -1.856 & 0.063 & & \\
\hline second-line & & 0.828 & 0.679 & 1.009 & -1.873 & 0.061 & & \\
\hline Overall & & 0.874 & 0.729 & 1.049 & -1.444 & 0.149 & & \\
\hline & & & & & & & 0.01 & 0.1 \\
\hline
\end{tabular}

Figure 3: Fixed-effect model of hazard ratio $(95 \% \mathrm{CI})$ of $\mathrm{OS}$ associated with therapy with or without anti-VEGF agents. 
Our systematic review is, as far as we known, the first systematic review to specially assess the efficacy of anti-VEGF agents in the treatment of elderly HCC patients. Our study includes a total of 1,309 elderly (aged $\geq 65$ years) HCC patients from seven trials. Our results demonstrate that the use of anti-VEGF agents MTAs in patients aged $\geq 65$ years significantly improves PFS (HR 0.65, 95\% CI: 0.55-0.76, $p<0.001$ ) but not for OS (HR 0.87, 95\% CI: $0.73-1.05, p=0.15$ ). Subgroup analysis according to treatment line shows that the use of anti-VEGF agents as second-line treatment significantly improves PFS (HR 0.55, 95\% CI: $0.45-0.67$, $p<0.001$ ) and marginally improves OS (HR $0.83,95 \%$ CI: $0.68-1.01, p=0.061$ ). Additionally, no survival benefits is observed in elderly HCC received first-line anti-VEGF treatments in terms of PFS (HR 0.87, 95\% CI: $0.67-1.13, p=0.29$ ) and OS (HR 1.19, 95\% CI: 0.74-1.36, $p=0.47$ ). The findings of this study suggest that elderly HCC patients who relapsed after a first-line sorafenib treatment obtain a survival benefits from rechallenge use of anti-VEGF agents. Further studies are recommended to search for predictors of good responders in these patients received anti-VEGF agents.

Several limitations exist in this analysis. First of all, this is a meta-analysis at study level. We could not obtain individual patient data from the publication, thus we could not incorporate patients variables into the analysis. Second, there is moderate heterogeneity among the included studies, because different anti-VEGF agents are included for analysis. Additionally, the patient population in the present study is significantly heterogeneous, which might be another source of heterogeneity. However, clinical heterogeneity might improve the generalizability of the observed results. Third, none of the included trials report the toxicities of anti-VEGF agents in elderly patients. Thus, we could not answer whether the use of anti-VEGF agents in this patient population would increase the toxicities in comparison with controls. Finally, publication bias is an important issue in the meta-analysis. In the present, we detect no publication bias using Begg and Egger tests for OS and PFS.

\section{CONCLUSIONS}

The findings of this study show that elderly HCC patients who relapsed after the first-line sorafenib treatment obtains a survival benefits from anti-VEGF agents rechallenge. Further studies are recommended to search for predictors of good responders in these patients received anti-VEGF agents.

\section{CONFLICTS OF INTEREST}

All authors declare that they have no potential conflicts of interests.

\section{FUNDING}

None.

\section{REFERENCES}

1. Jemal A, Bray F, Center MM, Ferlay J, Ward E, Forman D. Global cancer statistics. CA Cancer J Clin. 2011; 61:69-90.

2. Arzumanyan A, Reis HM, Feitelson MA. Pathogenic mechanisms in HBV- and HCV-associated hepatocellular carcinoma. Nat Rev Cancer. 2013; 13:123-135.

3. European Association For The Study Of The Liver; European Organisation For Research And Treatment Of Cancer. EASL-EORTC clinical practice guidelines: management of hepatocellular carcinoma. J Hepatol. 2012; 56:908-943.

4. Giannini EG, Farinati F, Ciccarese F, Pecorelli A, Rapaccini GL, Di Marco M, Benvegnu L, Caturelli E, Zoli M, Borzio F, Chiaramonte M, Trevisani F, Italian Liver Cancer (ITA.LI.CA) group. Prognosis of untreated hepatocellular carcinoma. Hepatology. 2015; 61:184-190.

5. Borzio M, Dionigi E, Vitale A, Rossini A, Marignani M, Fornari F, Vicari S, De Sio I, Farinati F, Bertolini E, Oliveri F, Leandro G, Francica G, et al. Management and prognosis of hepatocellular carcinoma in the elderly: Results of an in-field multicenter cohort study. Liver Int. 2017; 37:1184-1192.

6. Colagrande S, Inghilesi AL, Aburas S, Taliani GG, Nardi C, Marra F. Challenges of advanced hepatocellular carcinoma. World J Gastroenterol. 2016; 22:7645-7659.

7. Borzio M, Dionigi E, Parisi G, Raguzzi I, Sacco R. Management of hepatocellular carcinoma in the elderly. World J Hepatol. 2015; 7:1521-1529.

8. Folkman J. Tumor angiogenesis: therapeutic implications. N Engl J Med. 1971; 285:1182-1186.

9. Folkman J. Anti-angiogenesis: new concept for therapy of solid tumors. Ann Surg. 1972; 175:409-416.

10. Folkman J. Role of angiogenesis in tumor growth and metastasis. Semin Oncol. 2002; 29:15-18.

11. Thillai K, Ross P, Sarker D. Molecularly targeted therapy for advanced hepatocellular carcinoma - a drug development crisis? World J Gastrointest Oncol. 2016; 8:173-185.

12. Al-Husein B, Abdalla M, Trepte M, Deremer DL, Somanath PR. Antiangiogenic therapy for cancer: an update. Pharmacotherapy. 2012; 32:1095-1111.

13. Xie B, Wang DH, Spechler SJ. Sorafenib for treatment of hepatocellular carcinoma: a systematic review. Dig Dis Sci. 2012; 57:1122-1129.

14. Kelly WK, Halabi S, Carducci M, George D, Mahoney JF, Stadler WM, Morris M, Kantoff P, Monk JP, Kaplan E, Vogelzang NJ, Small EJ. Randomized, double-blind, placebo-controlled phase III trial comparing docetaxel and prednisone with or without bevacizumab in men with 
metastatic castration-resistant prostate cancer: CALGB 90401. J Clin Oncol. 2012; 30:1534-1540.

15. van der Graaf WT, Blay JY, Chawla SP, Kim DW, BuiNguyen B, Casali PG, Schoffski P, Aglietta M, Staddon AP, Beppu Y, Le Cesne A, Gelderblom H, Judson IR, et al. Pazopanib for metastatic soft-tissue sarcoma (PALETTE): a randomised, double-blind, placebo-controlled phase 3 trial. Lancet. 2012; 379:1879-1886.

16. Garon EB, Ciuleanu TE, Arrieta O, Prabhash K, Syrigos KN, Goksel T, Park K, Gorbunova V, Kowalyszyn RD, Pikiel J, Czyzewicz G, Orlov SV, Lewanski CR, et al. Ramucirumab plus docetaxel versus placebo plus docetaxel for secondline treatment of stage IV non-small-cell lung cancer after disease progression on platinum-based therapy (REVEL): a multicentre, double-blind, randomised phase 3 trial. Lancet. 2014; 384:665-673.

17. Grothey A, Van Cutsem E, Sobrero A, Siena S, Falcone A, Ychou M, Humblet Y, Bouche O, Mineur L, Barone C, Adenis A, Tabernero J, Yoshino T, et al. Regorafenib monotherapy for previously treated metastatic colorectal cancer (CORRECT): an international, multicentre, randomised, placebo-controlled, phase 3 trial. Lancet. 2013; 381:303-312.

18. Kontovinis LF, Papazisis KT, Touplikioti P, Andreadis C, Mouratidou D, Kortsaris AH. Sunitinib treatment for patients with clear-cell metastatic renal cell carcinoma: clinical outcomes and plasma angiogenesis markers. BMC Cancer. 2009; 9:82.

19. Abou-Alfa GK, Schwartz L, Ricci S, Amadori D, Santoro A, Figer A, De Greve J, Douillard JY, Lathia C, Schwartz B, Taylor I, Moscovici M, Saltz LB. Phase II study of sorafenib in patients with advanced hepatocellular carcinoma. J Clin Oncol. 2006; 24:4293-4300.

20. Llovet JM, Ricci S, Mazzaferro V, Hilgard P, Gane E, Blanc JF, de Oliveira AC, Santoro A, Raoul JL, Forner A, Schwartz M, Porta C, Zeuzem S, et al. Sorafenib in advanced hepatocellular carcinoma. N Engl J Med. 2008; 359:378-390.

21. Faivre S, Raymond E, Boucher E, Douillard J, Lim HY, Kim JS, Zappa M, Lanzalone S, Lin X, Deprimo S, Harmon C, Ruiz-Garcia A, Lechuga MJ, et al. Safety and efficacy of sunitinib in patients with advanced hepatocellular carcinoma: an open-label, multicentre, phase II study. Lancet Oncol. 2009; 10:794-800.

22. Cheng AL, Kang YK, Lin DY, Park JW, Kudo M, Qin S, Chung HC, Song X, Xu J, Poggi G, Omata M, Pitman Lowenthal S, Lanzalone $\mathrm{S}$, et al. Sunitinib versus sorafenib in advanced hepatocellular cancer: results of a randomized phase III trial. J Clin Oncol. 2013; 31:4067-4075.

23. Johnson PJ, Qin S, Park JW, Poon RT, Raoul JL, Philip PA, Hsu CH, Hu TH, Heo J, Xu J, Lu L, Chao Y, Boucher E, et al. Brivanib versus sorafenib as first-line therapy in patients with unresectable, advanced hepatocellular carcinoma: results from the randomized phase III BRISK-FL study. J Clin Oncol. 2013; 31:3517-3524.
24. Santoro A, Rimassa L, Borbath I, Daniele B, Salvagni S, Van Laethem JL, Van Vlierberghe H, Trojan J, Kolligs FT, Weiss A, Lu L, Chao Y, Boucher E, et al. Tivantinib for second-line treatment of advanced hepatocellular carcinoma: a randomised, placebo-controlled phase 2 study. Lancet Oncol. 2013; 14:55-63.

25. Cainap C, Qin S, Huang WT, Chung IJ, Pan H, Cheng Y, Kudo M, Kang YK, Chen PJ, Toh HC, Gorbunova V, Eskens FA, Qian J, et al. Linifanib versus Sorafenib in patients with advanced hepatocellular carcinoma: results of a randomized phase III trial. J Clin Oncol. 2015; $33: 172-179$.

26. Hung AK, Guy J. Hepatocellular carcinoma in the elderly: Meta-analysis and systematic literature review. World J Gastroenterol. 2015; 21:12197-12210.

27. Brunot A, Le Sourd S, Pracht M, Edeline J. Hepatocellular carcinoma in elderly patients: challenges and solutions. J Hepatocell Carcinoma. 2016; 3:9-18.

28. Moher D, Cook DJ, Eastwood S, Olkin I, Rennie D, Stroup DF. Improving the quality of reports of metaanalyses of randomised controlled trials: the QUOROM statement. Quality of Reporting of Meta-analyses. Lancet. 1999; 354:1896-1900.

29. Zintzaras E, Ioannidis JP. Heterogeneity testing in metaanalysis of genome searches. Genet Epidemiol. 2005; 28:123-137.

30. Vandenbroucke JP. Bias in meta-analysis detected by a simple, graphical test. Experts' views are still needed. BMJ. 1998; 316:469-470; author reply 470-461.

31. Jadad AR, Moore RA, Carroll D, Jenkinson C, Reynolds DJ, Gavaghan DJ, McQuay HJ. Assessing the quality of reports of randomized clinical trials: is blinding necessary? Control Clin Trials. 1996; 17:1-12.

32. Kang YK, Yau T, Park JW, Lim HY, Lee TY, Obi S, Chan SL, Qin S, Kim RD, Casey M, Chen C, Bhattacharyya H, Williams JA, et al. Randomized phase II study of axitinib versus placebo plus best supportive care in second-line treatment of advanced hepatocellular carcinoma. Ann Oncol. 2015; 26:2457-2463.

33. Cheng AL, Kang YK, Chen Z, Tsao CJ, Qin S, Kim JS, Luo R, Feng J, Ye S, Yang TS, Xu J, Sun Y, Liang H, et al. Efficacy and safety of sorafenib in patients in the AsiaPacific region with advanced hepatocellular carcinoma: a phase III randomised, double-blind, placebo-controlled trial. Lancet Oncol. 2009; 10:25-34.

34. Kudo M, Imanaka K, Chida N, Nakachi K, Tak WY, Takayama T, Yoon JH, Hori T, Kumada H, Hayashi N, Kaneko S, Tsubouchi H, Suh DJ, et al. Phase III study of sorafenib after transarterial chemoembolisation in Japanese and Korean patients with unresectable hepatocellular carcinoma. Eur J Cancer. 2011; 47:2117-2127.

35. Kudo M, Han G, Finn RS, Poon RT, Blanc JF, Yan L, Yang J, Lu L, Tak WY, Yu X, Lee JH, Lin SM, Wu C, et al. Brivanib as adjuvant therapy to transarterial chemoembolization in 
patients with hepatocellular carcinoma: A randomized phase III trial. Hepatology. 2014; 60:1697-1707.

36. Bruix J, Takayama T, Mazzaferro V, Chau GY, Yang J, Kudo M, Cai J, Poon RT, Han KH, Tak WY, Lee HC, Song T, Roayaie S, et al. Adjuvant sorafenib for hepatocellular carcinoma after resection or ablation (STORM): a phase 3, randomised, double-blind, placebo-controlled trial. Lancet Oncol. 2015; 16:1344-1354.

37. Zhu AX, Park JO, Ryoo BY, Yen CJ, Poon R, Pastorelli D, Blanc JF, Chung HC, Baron AD, Pfiffer TE, Okusaka T, Kubackova K, Trojan J, et al. Ramucirumab versus placebo as second-line treatment in patients with advanced hepatocellular carcinoma following first-line therapy with sorafenib (REACH): a randomised, double-blind, multicentre, phase 3 trial. Lancet Oncol. 2015; 16:859-870.

38. Bruix J, Qin S, Merle P, Granito A, Huang YH, Bodoky G, Pracht M, Yokosuka O, Rosmorduc O, Breder V, Gerolami R, Masi G, Ross PJ, et al. Regorafenib for patients with hepatocellular carcinoma who progressed on sorafenib treatment (RESORCE): a randomised, double-blind, placebo-controlled, phase 3 trial. Lancet. 2017; 389:56-66.

39. Yoshiji H, Kuriyama S, Yoshii J, Ikenaka Y, Noguchi R, Hicklin DJ, Wu Y, Yanase K, Namisaki T, Kitade M,
Yamazaki M, Tsujinoue H, Masaki T, et al. Halting the interaction between vascular endothelial growth factor and its receptors attenuates liver carcinogenesis in mice. Hepatology. 2004; 39:1517-1524.

40. Yao DF, Wu XH, Zhu Y, Shi GS, Dong ZZ, Yao DB, Wu W, Qiu LW, Meng XY. Quantitative analysis of vascular endothelial growth factor, microvascular density and their clinicopathologic features in human hepatocellular carcinoma. Hepatobiliary Pancreat Dis Int. 2005; 4:220-226.

41. Makinen T, Veikkola T, Mustjoki S, Karpanen T, Catimel B, Nice EC, Wise L, Mercer A, Kowalski H, Kerjaschki D, Stacker SA, Achen MG, Alitalo K. Isolated lymphatic endothelial cells transduce growth, survival and migratory signals via the VEGF-C/D receptor VEGFR-3. EMBO J. 2001; 20:4762-4773.

42. Niu M, Hong D, Ma TC, Chen XW, Han JH, Sun J, Xu K. Short-term and long-term efficacy of 7 targeted therapies for the treatment of advanced hepatocellular carcinoma: a network meta-analysis: Efficacy of 7 targeted therapies for AHCC. Medicine (Baltimore). 2016; 95:e5591. 